Article

\title{
Raindrop Energy Impact on the Distribution Characteristics of Splash Aggregates of Cultivated Dark Loessial Cores
}

\author{
Yu Fu ${ }^{1}$, Guanglu Li ${ }^{1,2, *}$, Dong Wang ${ }^{2}$, Tenghui Zheng ${ }^{1}$ and Mingxi Yang ${ }^{2}$ \\ 1 Institute of Soil and Water Conservation, Northwest A\&F University, No. 26 Xinong Road, \\ Yangling 712100, China \\ 2 College of Resources and Environment, Northwest A\&F University, No. 3 Taicheng Road, \\ Yangling 712100, China \\ * Correspondence: guangluli@nwsuaf.edu.cn; Tel.: +86-029-87082376
}

Received: 15 June 2019; Accepted: 18 July 2019; Published: 21 July 2019

\begin{abstract}
To determine the effect of different rainfall energy levels on the breakdown of soil aggregates, this study analyzed the soil splash erosion amounts and the distribution of particle sizes under six rainfall conditions (rainfall energy: $2.41 \times 10^{-5}-22.4 \times 10^{-5} \mathrm{~J} \mathrm{~m}^{-2} \mathrm{~s}^{-1}$ and $1.29 \times 10^{-4} \mathrm{~J} \mathrm{~m}^{-2} \mathrm{~s}^{-1}$ ) at five splash distances (from 0-10 cm to $40-50 \mathrm{~cm}$ ). Cores of the size $10 \times 20 \mathrm{~cm}$ of undisturbed cultivated dark loessial soil were selected in tree replicates as the research subject. The results indicated that splashed aggregates were distributed mainly at splash distances of 0-20 cm, which accounted for $66 \%-90 \%$ of the total splash erosion amount. The splash erosion amount significantly decreased exponentially with increasing splash distance for the same rainfall energy $(p<0.01)$. The splash erosion amount significantly increased in the power function relationship with increasing rainfall energy at the same splash distance $(p<0.05)$. A model was obtained to predict the splash erosion amount for rainfall energy and splash distance. The fractal dimension $(D)$ of the aggregates showed a downward opening parabolic relationship with raindrop energy. The maximal value of the rainfall energy was $1.286 \times 10^{-4} \mathrm{~J} \mathrm{~m}^{-2} \mathrm{~s}^{-1}$, which broke the aggregates to the largest degree. Enrichment ratio $(E R)$ values for fragments $>2 \mathrm{~mm}$ were close to 0 . A particle size of $0.25 \mathrm{~mm}$ was the critical particle level for splash erosion.
\end{abstract}

Keywords: raindrop energy; soil aggregate; splash distance; fractal dimension; Loess Plateau

\section{Introduction}

Soil erosion reduces land productivity and soil fertility, destroys farmland, exacerbates flood disasters, and results in soil environment deterioration, which affects land exploitation and the protection and utilization of soil and water resources [1,2]. Water erosion is the main type of soil erosion in the Loess Plateau. The aggregates caused by splash erosion are dispersed and broken, which is the initial stage of water erosion [1-4]. Raindrops fall from the air and impact the surface soil particles at a certain speed under the action of gravity. Some soil particles are separated from the soil and become loose particles, which is conducive to the formation and flow of surface runoff. At the same time, the process provides abundant loose particles for subsequent runoff transport $[5,6]$. Additionally, soil particle transport leads to reduced or blocked pores on the soil surface and reduced soil permeability due to soil crust formation [7-9].

At present, research on splash erosion can be divided into two methods: Natural rainfall and artificial simulated rainfall. The observation of natural rainfall requires a long timeframe, and many factors are difficult to control, which makes the collection of splash data difficult. Artificial simulated rainfall can make up for shortages of natural rainfall and improve the feasibility of testing and reliability 
of the data. Rainfall characteristics include raindrop diameter, rainfall intensity, raindrop kinetic energy, and so on. The effect of rainfall intensity on raindrop diameter and rainfall was studied by Yakubu et al. [10], who proposed that the relationship between raindrop diameter and rainfall intensity could be expressed as an exponential or power function relationship. Sajjadi and Mahmoodabadi [11] carried out raindrop splashing tests under two different rainfall intensities $\left(57 \mathrm{~mm} \mathrm{~h}^{-1}\right.$ and $\left.80 \mathrm{~mm} \mathrm{~h}^{-1}\right)$. The results showed that the splash erosion amounts of fine particles with sizes $<0.043 \mathrm{~mm}$ were greater than those of large particles under a higher rainfall intensity. Moreover, with increasing rainfall duration, the rate of the total splash erosion observed at the beginning of the rainfall reaches a peak value: The larger the rainfall intensity, the less time it takes to reach the peak value [12]. Ziadat and Taimeh [13] reported that soil erosion on cultivated land was primarily affected by moisture content, whereas on uncultivated land it was mostly affected by slope steepness. Lim et al. [14] suggested that a power function relationship existed between raindrop energy and rainfall intensity. Free [15] showed that the splash erosion amount was positively correlated with rainfall energy and that raindrop energy was an important index to evaluate the degree of soil erosion caused by rainfall [14]. Rainfall intensity, raindrop energy, and their variations in time and space have important effects on the prediction of rainfall erosion $[16,17]$.

At present, most research on raindrop energy for splash erosion has used a raindrop device to simulate natural rainfall [18] and control the raindrop energy by adjusting the rainfall intensity or height [16,19-21]. However, the rainfall energy of natural rainfall simulated by a raindrop generator is instantaneous energy, which has a range of changes, and an increase or decrease in the energy has a significant impact on the amount of raindrop splash erosion. Therefore, a raindrop generator with constant raindrop energy should be used for experimental studies to ensure that the results of the study are more accurate. The splash collection device was mainly composed of an Ellison splashing pan [22], an Ellison splashing cup [23], and a Morgan splashing pan [24]. The improved device [20,25,26] could collect most soil splash erosion particles, but the horizontal spatial distribution of the splash amount and particle size have been less well studied. Furthermore, most previous studies have used dried soil [27] or disturbed soil [20,28], which destroyed the soil structure and reduced the reliability of the data.

The objectives of this study were to (i) clarify the effect of raindrop energy on the splash distance and particle size distribution of aggregate splash erosion, (ii) establish a prediction equation for splash erosion in this area, and (iii) predict whether a certain raindrop energy will break up the aggregates to a great extent by comparing the characteristic parameters of the aggregate fractions.

\section{Materials and Methods}

\subsection{Sampling Site and Soil Properties}

The sampling site is located in the Changwu agriculture ecological experimental station, Weibei Plateau, Xianyang, Shanxi province $\left(107^{\circ} 40^{\prime} 59^{\prime \prime} \mathrm{E}, 35^{\circ} 14^{\prime} 27^{\prime \prime} \mathrm{N}\right)$, and has an annual average temperature of $9.1^{\circ} \mathrm{C}$ and annual average precipitation of $580.0 \mathrm{~mm}$. The zonal soil is dark loessial soil [29]. The soil is loose, and the permeability is good, resulting in a good "soil reservoir" effect. The international soil texture classification is loam soil according to the USDA (United States Department of Agriculture) particle size classification criteria. Twenty-one samples and $1000 \mathrm{~g}$ of scattered soil were collected from the top layer $(0-20 \mathrm{~cm})$ of cultivated land using a cutting ring $(10 \mathrm{~cm}$ diameter $\times 5 \mathrm{~cm}$ height $)$ and the diagonal method. Three of the samples were used to determine the soil bulk density and moisture content, and the remaining 18 samples were used for the raindrop splash experiment. After the scattered soil dried naturally, the bulk density, moisture content, soil organic matter, total nitrogen, total phosphorus, and mechanical components were determined using the cutting ring (determine the bulk density and moisture content), potassium dichromate external heating, Kjeldahl nitrogen, $\mathrm{HClO}_{4}-\mathrm{H}_{2} \mathrm{SO}_{4}$, and Malvin laser particle sizer methods. The soil characteristics of the sampling sites are reported in Table 1. 
Table 1. Physical and chemical properties of the soil.

\begin{tabular}{|c|c|c|c|c|c|c|c|c|}
\hline \multirow[b]{2}{*}{$\begin{array}{l}\text { Soil } \\
\text { Type }\end{array}$} & \multirow{2}{*}{$\begin{array}{c}\text { Bulk } \\
\text { Density/ } \\
\left(\mathrm{g} \cdot \mathrm{cm}^{-3}\right)\end{array}$} & \multirow[b]{2}{*}{$\begin{array}{l}\text { Moisture } \\
\text { Content/\% }\end{array}$} & \multirow[b]{2}{*}{$\begin{array}{c}\text { Soil Organic } \\
\text { Carbon/\% }\end{array}$} & \multirow{2}{*}{$\begin{array}{c}\text { Total } \\
\text { Nitrogen/ } \\
\left(\mathrm{g} \cdot \mathrm{kg}^{-1}\right)\end{array}$} & \multirow{2}{*}{$\begin{array}{c}\text { Total } \\
\text { Phosphorus/ } \\
\text { (g. } \text { kg }^{-1} \text { ) }\end{array}$} & \multicolumn{3}{|c|}{ Particle Size Composition/\% } \\
\hline & & & & & & $\begin{array}{l}\text { Sand } \\
(2-0.02 \\
\mathrm{mm})\end{array}$ & $\begin{array}{c}\text { Silt } \\
(0.02-0.002 \\
\text { mm) }\end{array}$ & $\begin{array}{c}\text { Clay } \\
(<0.002 \mathrm{~mm})\end{array}$ \\
\hline \multirow[b]{2}{*}{$\begin{array}{c}\text { Dark } \\
\text { loessial } \\
\text { soil }\end{array}$} & $1.1 \pm 0.1$ & $18.8 \pm 1.0$ & $1.6 \pm 0.1$ & $1.0 \pm 0.1$ & $0.7 \pm 0.03$ & $52.3 \pm 0.5$ & $37.4 \pm 0.03$ & $10.3 \pm 0.04$ \\
\hline & $\begin{array}{l}>2 \mathrm{~mm} \\
6.9 \pm 1.8\end{array}$ & $\begin{array}{c}1-2 \mathrm{~mm} \\
12.3 \pm 1.1\end{array}$ & $\begin{array}{l}\quad \text { Fra } \\
0.5-1 \mathrm{~mm} \\
21.3 \pm 4.2\end{array}$ & $\begin{array}{r}\text { ment size di } \\
0.25- \\
21 .\end{array}$ & $\begin{array}{l}\text { stribution of th } \\
0.5 \mathrm{~mm} \\
\pm 2.1\end{array}$ & $\begin{array}{r}\text { undisturbe } \\
0.053 \\
14\end{array}$ & $\begin{array}{l}\mathrm{soil} / \% \\
.25 \mathrm{~mm} \\
\pm 4.1\end{array}$ & $\begin{array}{l}<0.053 \mathrm{~mm} \\
23.9 \pm 2.9\end{array}$ \\
\hline
\end{tabular}

\subsection{Experimental Design}

The artificial rainfall device used in this study consisted of two parts: A raindrop generator and a splashed raindrop-collecting device (Figure 1) [30]. The raindrop generator was a cylindrical box with an open top (10 cm in diameter and $10 \mathrm{~cm}$ in height). Twenty-one syringe needles were installed in the floor of the box, and different needles could generate different raindrop diameters. A stainless steel pan (110 cm diameter) containing six concentric circles composed of wire was selected as the splash raindrop-collecting device. The splash pan was centered in a circle and was used to place the open cutting ring ( $10 \mathrm{~cm}$ diameter $\times 5 \mathrm{~cm}$ height). In turn, the edge of the cutting ring contained fenced concentric circles with wire at distances of $10 \mathrm{~cm}, 20 \mathrm{~cm}, 30 \mathrm{~cm}, 40 \mathrm{~cm}$, and $50 \mathrm{~cm}$. The area between the splash pan and wire was impermeable. Each concentric circle was set symmetrically with two drains, which were used to collect splashed soil particles. Outside of the experimental device, a baffle and plastic cover were placed to prevent the effects of horizontal airflow disturbance on the rainfall.

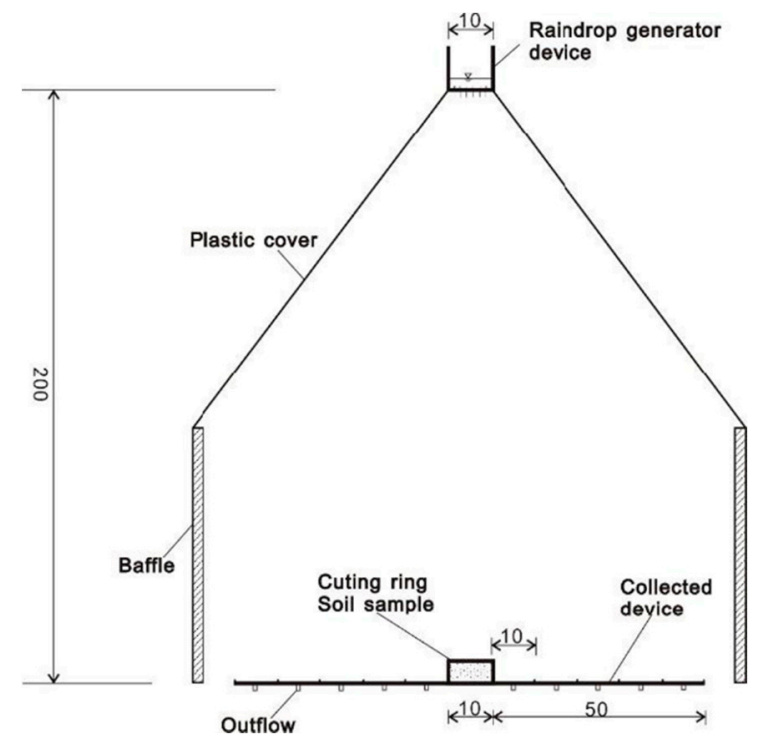

Figure 1. The test for splashed raindrops and soil aggregates (unit: $\mathrm{cm}$ ). Note: the figure is from Fu et al. [30].

Six raindrop energy levels determined by six raindrop diameters and the height of the rainfall $(2 \mathrm{~m})$ were selected in the experiment. The corresponding six raindrop diameters were $2.67 \mathrm{~mm}, 3.05 \mathrm{~mm}$, $3.39 \mathrm{~mm}, 3.79 \mathrm{~mm}, 4.05 \mathrm{~mm}$, and $5.45 \mathrm{~mm}$. The raindrop energy was calculated by the following method: When the raindrop diameter was greater than or equal to $1.9 \mathrm{~mm}$, the final velocity of the raindrops was calculated using a modified Newton formula (Equation (1)). Equation (2) was used to calculate the raindrop velocity under this test condition [31]. The raindrop energy was calculated by Equation (3). Therefore, the final raindrop energy levels were $2.41 \times 10^{-5}, 3.68 \times 10^{-5}, 5.15 \times 10^{-5}$, $7.30 \times 10^{-5}, 8.97 \times 10^{-5}$, and $22.4 \times 10^{-5} \mathrm{~J} \mathrm{~m}^{-2} \mathrm{~s}^{-1}$, which conformed to the range of natural rainfall 
raindrop energy. The corresponding rainfall intensities and rainfall diameters all conformed to the rainfall characteristics of the Loess Plateau [32]. Equations (1)-(3) are

$$
\begin{gathered}
V_{i}=(17.20-0.84 d) \sqrt{0.1 d}, d>1.9, \\
V=V_{i} \sqrt{1-e^{-\frac{2 g}{V_{i}^{2}} H},} \\
E_{r S}=\sum_{i=1}^{n} \frac{1}{2} \mathrm{mV}^{2},
\end{gathered}
$$

where $V$ is the raindrop velocity $\left(\mathrm{m} \mathrm{s}^{-1}\right), d$ is the raindrop diameter $(\mathrm{mm}), V_{i}$ is the terminal velocity $\left(\mathrm{m} \mathrm{s}^{-1}\right), H$ is the height of the falling raindrop $(\mathrm{m}), E_{r s}$ is the raindrop energy $\left(\mathrm{J} \mathrm{m}^{-2} \mathrm{~s}^{-1}\right), m$ is the individual raindrop mass $(\mathrm{g}), i=0, \ldots, n$ is the number of raindrops, and $g$ is gravity acceleration $\left(\mathrm{m} \mathrm{s}^{-2}\right)$.

Prior to the start of the test, the water head height was adjusted to $2 \mathrm{~cm}$. All of the needles started to drop raindrops at the same time. The rainfall duration was $10 \mathrm{~min}$, and all tests were replicated 3 times. The splashed fragments were collected for each of the five distances $(0-10 \mathrm{~cm}, 10-20 \mathrm{~cm}$, 20-30 cm, 30-40 cm, and 40-50 cm). An aggregate analyzer (HR-TTF-100, Shunlong Experiment Instrument Factory, Yuxi City, Zhejiang province, China) was used to sieve the fragments into size fractions of $>2 \mathrm{~mm}, 1-2 \mathrm{~mm}, 0.5-1 \mathrm{~mm}, 0.25-0.5 \mathrm{~mm}, 0.053-0.25 \mathrm{~mm}$, and $<0.053 \mathrm{~mm}$, which then were oven-dried for $24 \mathrm{~h}$ at $105{ }^{\circ} \mathrm{C}$ and weighed. A new test plot was prepared after each rainfall event.

\subsection{Parameter Calculation}

This study used the fractal dimension $(D)$ proposed by Yang [33] with the quality of the particle size distribution described in the soil fractal model as follows:

$$
\frac{W\left(\delta>d_{i}\right)}{W_{0}}=1-\left(\frac{d_{i}}{d_{\max }}\right)^{3-D} \text {. }
$$

Take the exponential of both sides,

$$
\frac{W\left(\delta>d_{i}\right)}{W_{0}}=(3-D) \lg \left(\frac{d_{i}}{d_{\max }}\right)
$$

where $W\left(\delta>d_{i}\right)$ is the cumulative mass of soil particles with size $\delta$ more than a comparative size $d_{i}, W_{0}$ is the total mass of the particles, $d_{i}$ is the average of the sieve size range $(d j, d j+1)$, and $d_{\max }$ is the maximum particle size.

For each size fraction, the enrichment ratio $(E R)$ refers to the mass percentage of splash sediment compared to the undisturbed aggregates. An $E R$ value $>1$ indicates enrichment of the fraction, whereas an $E R$ value $<1$ demonstrates that the fraction is depleted. The $E R$ is calculated as

$$
E R=\frac{P_{s p}}{P_{s a}}
$$

where $P_{s p}$ is the mass percentage of one size fraction in the total mass of splash aggregates, and $P_{s a}$ is the mass percentage of one size fraction in the total mass of undisturbed aggregates.

Nash-Sutcliffe indices $\left(E_{N S}\right)$ [34] were used to evaluate the model prediction, which is a modeling efficiency metric ranging from negative infinity to 1 , where only $>0$ values are acceptable:

$$
E_{N S}=1-\frac{\sum_{i=1}^{n}\left(O_{i}-S_{i}\right)^{2}}{\sum_{i=1}^{n}\left(O_{i}-\bar{O}\right)^{2}},
$$

where $O_{i}$ is the $i$ th measured value of the mass of splash erosion, $S_{i}$ is the $i$ th predicted value of the mass of splash erosion, $n$ is the total number of measured values, and $\bar{O}$ is the mean of the measured 
values of the mass of splash erosion. Significant differences in the splash erosion amounts for different raindrop energies or different splash distances were detected using one-way analysis of variance (ANOVA), followed by the LSD test (Least-Significant Difference) $(p<0.05)$. The relationships between the splash erosion amount and splash distances, between the splash erosion amount and raindrop energy, and between the splash erosion amounts, splash distances, and raindrop energy levels were analyzed using a simple regression method. All statistical analyses were performed using SPSS 16.0 (IBM SPSS Software, Armonk, NY, USA), and all figures were processed in Origin 8.5 (OriginLab Corporation, Northampton, MA, USA).

\section{Results and Discussion}

\subsection{Distribution Characteristics of the Splash Erosion Amounts}

The distribution of the splash erosion amounts under the different raindrop energy levels is shown in Table 2. The splash erosion amount decreased with increasing splash distance for the same raindrop energy. The splash erosion amounts of the six raindrop conditions were distributed mainly at 0-20 cm, which accounted for $66 \%$ of the total splash erosion amount and was significantly higher than the splash erosion amounts at the other distances. The splash erosion amounts at 20-30 cm and 30-40 cm accounted for $16 \%$ and $10 \%$ of the total splash erosion amount, respectively. In addition, the amount of splash erosion that reached a distance of 40 to $50 \mathrm{~cm}$ accounted for $1 \%-8 \%$ of the total splash erosion amount, which was significantly less than for the other splash distances $(p<0.05)$. The raindrops collided with the surface soil to destroy the original soil structure, which caused them to disperse and spatter soil particles under the action of their own gravity via parabolic motion. Their movement paths were affected by their own weight and volume. Theoretically, when raindrop energy is the same, small-sized particles are transported longer distances because of their light mass, whereas large-sized particles remain at close distances [29]. Therefore, the amount of aggregate fractions at the 0-20 cm distance was significantly higher than that at the other splash distances. Regression analysis of the splash erosion amount $(M)$ and splash distance $(S)$ produced for the different raindrop energy levels showed that the splash amount $M$ decreased exponentially with increasing splash distance $S(p<0.01)$. The regression equation was $M=\operatorname{mexp}(n S)$, where $m$ and $n$ are the parameters (Table 3). This result was consistent with those of the studies of Dijk et al. [26], Cheng et al. [12], and Fu et al. [30].

Table 2. Amounts of splash erosion at different distances for different raindrop energy levels.

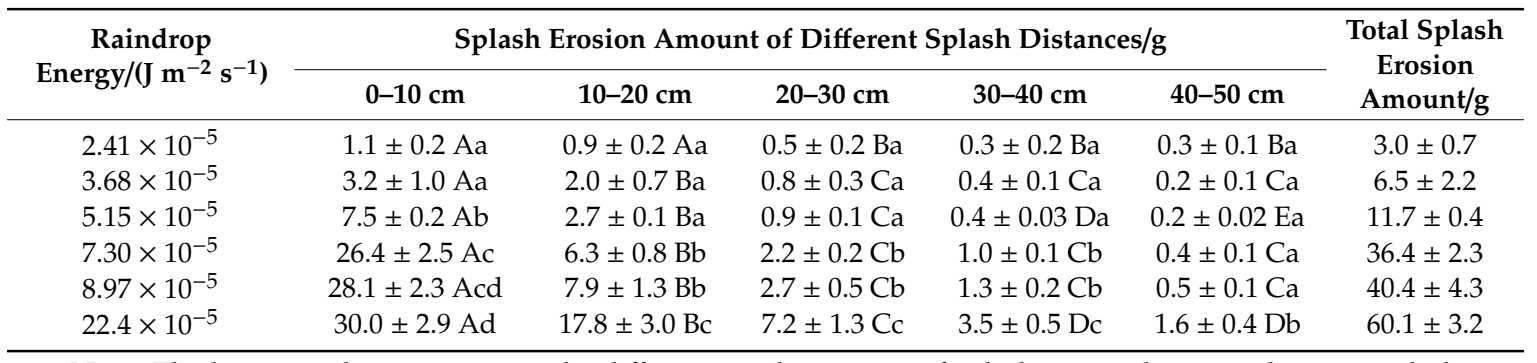

Note: The lowercase letters represent the difference in the amount of splash erosion between the same splash distance and different raindrop energy levels, and the uppercase letters denote the difference in splash amount between the same raindrop energy level and different splash distances. There was no significant difference in the values of each column or line with the same letter $(p>0.05)$. 
Table 3. Relationships between the amounts of splash $(M)$ and the splash distance $(S)$ for different raindrop energy levels.

\begin{tabular}{ccccc}
\hline $\begin{array}{c}\text { Raindrop Energy/(J m } \\
\mathbf{s}^{-\mathbf{1}} \mathbf{)}\end{array}$ & Simulated Equation & $\boldsymbol{R}^{\mathbf{2}}$ & $\boldsymbol{p}$-Value & $\boldsymbol{n}$ \\
\hline $2.41 \times 10^{-5}$ & $M=1.725 \times \mathrm{e}^{-0.040 S}$ & 0.976 & $<0.01$ & 30 \\
$3.68 \times 10^{-5}$ & $M=6.826 \times \mathrm{e}^{-0.0471 S}$ & 0.991 & $<0.01$ & 30 \\
$5.15 \times 10^{-5}$ & $M=16.553 \times \mathrm{e}^{-0.091 S}$ & 0.990 & $<0.01$ & 30 \\
$7.30 \times 10^{-5}$ & $M=57.291 \times \mathrm{e}^{-0.101 S}$ & 0.985 & $<0.01$ & 30 \\
$8.97 \times 10^{-5}$ & $M=61.771 \times \mathrm{e}^{-0.098 S}$ & 0.989 & $<0.01$ & 30 \\
$22.4 \times 10^{-5}$ & $M=68.814 \times \mathrm{e}^{-0.074 S}$ & 0.995 & $<0.01$ & 30 \\
\hline
\end{tabular}

When the splash distance was the same (Table 2), the splash erosion amount increased with increasing raindrop energy. The splash erosion amount of the raindrop energy $22.4 \times 10^{-5} \mathrm{~J} \mathrm{~m}^{-2} \mathrm{~s}^{-1}$ was at a maximum and was significantly higher than that of the other raindrop energies, which were 1.1-27.3, 2.3-20.0, 2.7-15.0, 2.7-10.9, and 3.1-6.7 times that of the other splash distances, respectively. The regression analysis showed that for the same splash distance, the splash erosion amount $M$ had a power function relationship with the raindrop energy $E$ (Table 4). These results were consistent with those of Hu et al. [20], Rose [35], Parsons et al. [36], and Fernándezraga et al. [37] and showed that the impact of the raindrop was enhanced by an increase in the raindrop energy, which then promoted the separation and transportation of more soil particles. The index value of the relationship between the total splash erosion amount and the raindrop energy was 1.42. This value was close to the index value of 1.46 from the study of Free [15]. However, Hu et al. [20] showed that the total soil splash erosion amount was a power function with increasing raindrop energy in the black soil area of the northeast Chinese mollisol region under rainfall intensities of $50 \mathrm{~mm} \mathrm{~h}^{-1}$ and $100 \mathrm{~mm} \mathrm{~h}^{-1}$ : Moreover, the index values were 2.79 and 1.69, respectively, which were different from the results of this study. This discrepancy may have been due to differences in the soil organic matter content between black loessial soil (SOM (Soil Organic Matter): 1.55\%) and the black soil area (SOM: 2.38\%), because the soil organic matter content may have affected soil erodibility. The relationship between the splash erosion amount and raindrop energy varied with increasing splash distances, and both the raindrop energy $(E)$ and splash distance $(S)$ affected the splash erosion amount $(M)$. For the $M$ values, $E$ values, and splash distances $S$ that were analyzed using multiple regression, the relationship followed a power-exponential function: $M=E^{0.72} \times 16.28 e^{12.92 \times S^{-0.21}}, R^{2}=0.81, p<0.05$. The data of Wang et al. [21] were placed into the above equation for verification. The $E_{N S}$ value was 0.67 (Figure 2a). It can be seen that the fit was better [34], which may have been because the soil used in Wang et al. [21] was from the Loess Plateau and the rainfall conditions were similar to this study. The data of Cheng et al. [12] were placed into the above equation for verification. The $E_{N S}$ value was less than 0 (Figure $2 b$ ). This may have been affected by soil types and slope. The data in this study were placed into the splash erosion model of Hu et al. [20]: $S_{T}=0.14 K E^{2.65} D_{50}{ }^{0.54}$, where $S_{T}$ is total splash erosion $(\mathrm{g}), K E$ is raindrop kinetic energy $\left(\mathrm{J} \mathrm{m}^{-2} \mathrm{~mm}^{-1}\right)$, and $D_{50}$ is the raindrop median volume diameter $(\mathrm{mm})$. The results showed that the $E_{N S}$ value was less than 0 (Figure 3), so the model of Hu et al. [20] could not predict the amount of splash erosion in this study, which was mainly affected by soil types and rainfall conditions. The above research further indicated that the model proposed in this study can evaluate soil splash erosion in the Loess Plateau well, but the simulation results of the areas outside the Loess Plateau are still insufficient. Therefore, model correction needs further exploration in future research. 
Table 4. Relationships between the splash erosion amount $(M)$ and raindrop energy $(E)$ at different splash distances.

\begin{tabular}{ccccc}
\hline Splash Distance & Simulated Equation & $\boldsymbol{R}^{\mathbf{2}}$ & $\boldsymbol{p}$-Value & $\boldsymbol{n}$ \\
\hline $0-10 \mathrm{~cm}$ & $M=3.332 \times 10^{7} E^{1.564}$ & 0.779 & $<0.05$ & 18 \\
$10-20 \mathrm{~cm}$ & $M=2.144 \times 10^{6} E^{1.365}$ & 0.964 & $<0.05$ & 18 \\
$20-30 \mathrm{~cm}$ & $M=3.325 \times 10^{5} E^{1.217}$ & 0.972 & $<0.05$ & 18 \\
$30-40 \mathrm{~cm}$ & $M=5.663 \times 10^{4} E^{1.159}$ & 0.942 & $<0.05$ & 18 \\
$40-50 \mathrm{~cm}$ & $M=3.511 \times 10^{3} E^{0.941}$ & 0.837 & $<0.05$ & 18 \\
$0-50 \mathrm{~cm}$ & $M=1.515 \times 10^{7} E^{1.421}$ & 0.872 & $<0.05$ & 18 \\
\hline
\end{tabular}

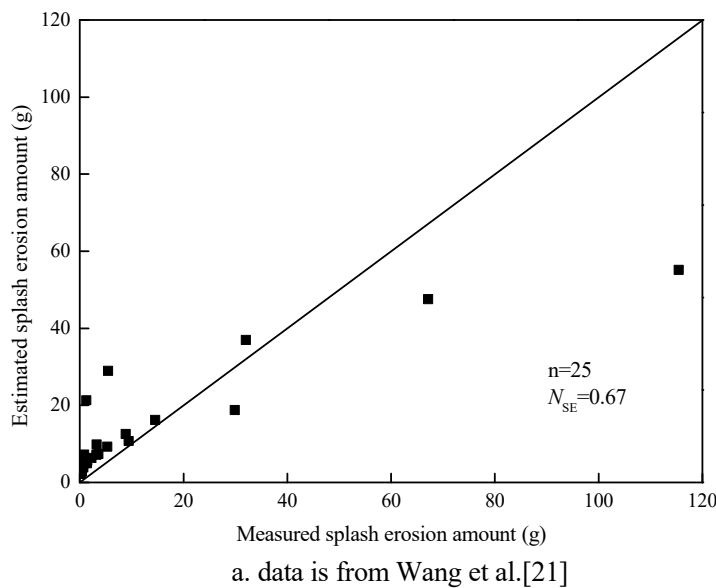

(a)

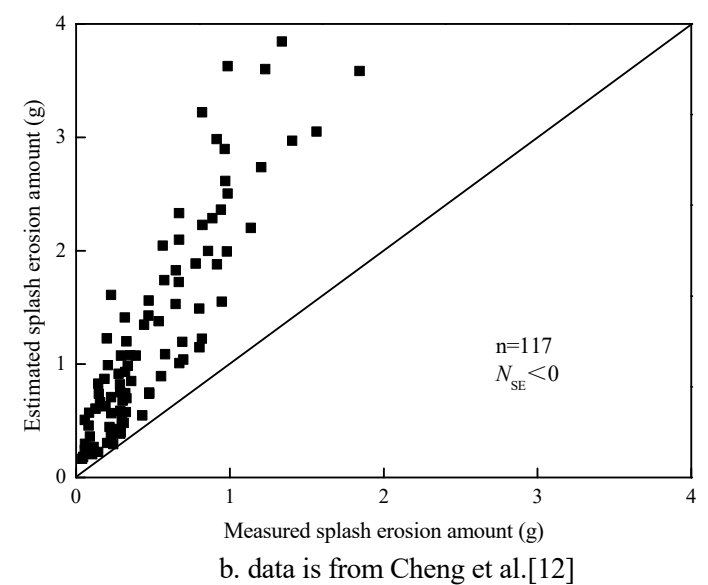

(b)

Figure 2. Comparison between the predicted and measured values of the splash erosion amount. (a) Data are from Wang et al. [21]; (b) data are from Cheng et al. [12].

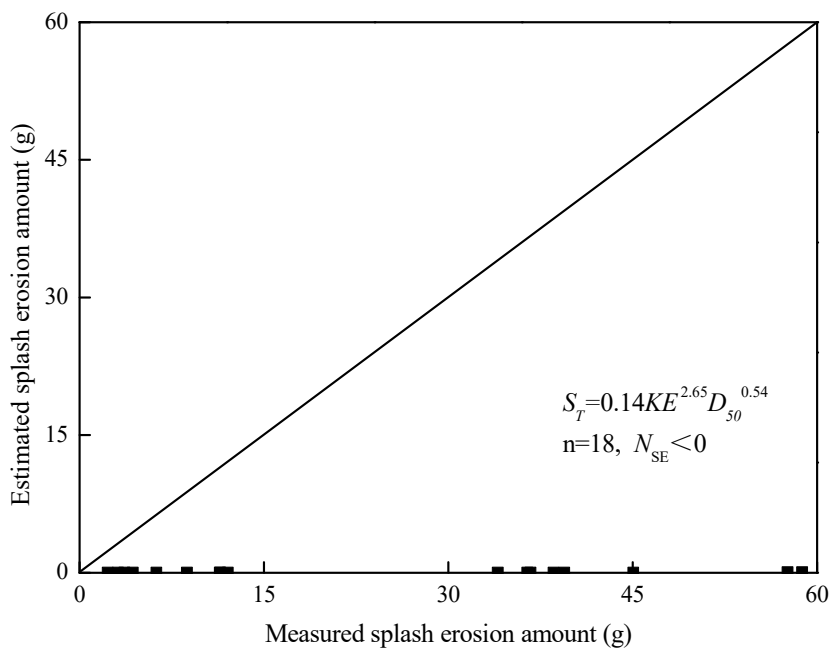

Figure 3. Comparison between the predicted and measured values of the splash erosion amount.

\subsection{Particle Size Distribution Characteristics of Splash Aggregate Fragments}

The particle size distribution of splashed aggregates for different raindrop energy levels is shown in Figure 4. For each raindrop energy level, the mass percentage of soil aggregates $>2 \mathrm{~mm}$ was almost zero, possibly because these aggregates were not sufficient to splash out under the present experimental conditions [25,30]. As a whole, the mass percentage of particle sizes $>0.25 \mathrm{~mm}$ presented a down up trend with increasing raindrop energy. When the raindrop energy was $2.41 \times 10^{-5} \mathrm{~J} \mathrm{~m}^{-2} \mathrm{~s}^{-1}$, the mass percentage of the water-stable aggregates $>0.25 \mathrm{~mm}$ was highest, with a value of $39 \%$. When the raindrop energy was $7.30 \times 10^{-5} \mathrm{~J} \mathrm{~m}^{-2} \mathrm{~s}^{-1}$, the mass percentage of 
water-stable aggregates $>0.25 \mathrm{~mm}$ in diameter was lowest, with a value of $18 \%$. This outcome may have been due to the smaller raindrop energy condition, in which the raindrop was less effective at soil splash erosion. With an increase in the raindrop energy, the effect of raindrops on soil aggregates was enhanced. Therefore, dispersed soil particles were more likely to be splashed, and some of the splashed aggregates broke into microaggregates $(<0.25 \mathrm{~mm})$. Due to the lighter mass of the microaggregates themselves, the quantity of transportation was larger. When the raindrop energy was higher than $7.30 \times 10^{-5} \mathrm{~J} \mathrm{~m}^{-2} \mathrm{~s}^{-1}$, more macroaggregates splashed out, and thus the mass percentage of the macroaggregates $(>0.25 \mathrm{~mm})$ increased.

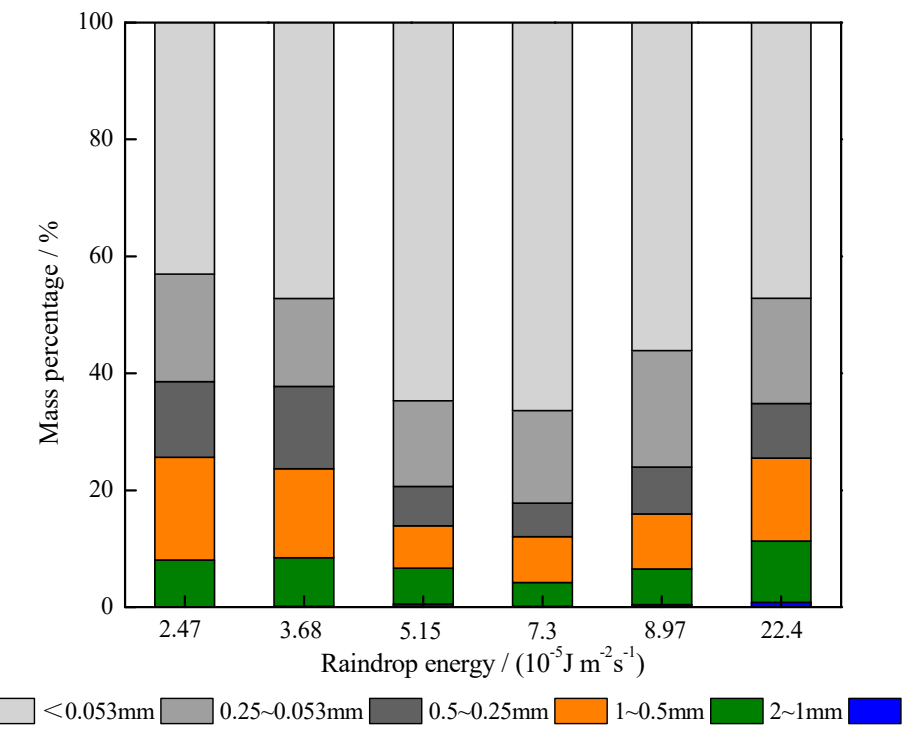

Figure 4. The particle size distribution of splashed aggregates for different raindrop energy levels.

\subsection{Effect of Raindrop Energy Levels on Characteristic Parameters of Splash Aggregate Fragments}

Castrignano [38] reported that larger $D$ values resulted in more dispersion of aggregates. Lower $D$ values of aggregates represented a particle size distribution dominated by larger fragments, whereas higher $D$ values reflected a distribution dominated by smaller fragments [39]. The fractal dimensions of the splash aggregate fragments for the six raindrop energy levels were 2.789, 2.798, 2.896, 2.898, 2.862 , and 2.818, respectively. Regression analysis of the fractal dimension and raindrop energy levels concluded that the fractal dimension of the soil splash aggregate $(D)$ clearly changed as a quadratic function, which presented an up-down trend with increasing raindrop energy $(E)$. The equation is $D=-1.0532 \times 10^{-4}\left(E-1.29 \times 10^{-4}\right)^{2}+2.564, R^{2}=0.627, p<0.05$. The maximal raindrop energy value was $1.29 \times 10^{-4} \mathrm{~J} \mathrm{~m}^{-2} \mathrm{~s}^{-1}$, which broke the aggregates to the largest degree. On the whole, the fractal dimension of the splash aggregate fragments for the raindrop energy of $2.41 \times 10^{-5} \mathrm{~J} \mathrm{~m}^{-2} \mathrm{~s}^{-1}$ was lower than that for $22.4 \times 10^{-5} \mathrm{~J} \mathrm{~m}^{-2} \mathrm{~s}^{-1}$. This difference may have been due to the lowest raindrop energy level, less splashing of aggregates, and a higher proportion of large particles splashed out due to their own mass. However, when the raindrop energy was larger, more macroaggregates splashed out, although some of them broke into microaggregates [28]: Therefore, the fractal dimension was relatively high.

The splash enrichment ratio $(E R)$ for each particle size at the different raindrop energy levels is shown in Figure 5. The enrichment ratio of aggregates presented an up-down trend with decreasing particle size. The $E R$ value for a particle size greater than $2 \mathrm{~mm}$ was close to 0 . Ma et al. [25] showed that a rainfall intensity of $58.1 \mathrm{~mm} \cdot \mathrm{h}^{-1}$ resulted in $E R$ values of 0 for particle sizes of $5-2 \mathrm{~mm}$ and a value close to 0 for particle sizes of $2-1 \mathrm{~mm}$, which was consistent with the results of this study. The $E R$ value for particle sizes greater than $0.25 \mathrm{~mm}$ was $<1$, whereas that for particle sizes less than $0.25 \mathrm{~mm}$ was $>1$ for all raindrop energy levels. Thus, the $0.25-\mathrm{mm}$ particle size was the critical particle size 
level for the enrichment and depletion of splash erosion. However, Zhou [40] analyzed the selective characteristics of splash erosion for black soil aggregates and concluded that aggregates with a particle size $>1.0 \mathrm{~mm}$ were not easily transported. Hence, a particle size of $1.0 \mathrm{~mm}$ was the critical particle level for the enrichment and depletion of splash erosion. This finding was inconsistent with the conclusion of this study, possibly because the soil selected in this study was developed from loess parent material, and the erodibility of the soil was relatively high. Under the condition of raindrop splash erosion, the large particle size was smaller and was easily broken into smaller particle-sized aggregates: Thus, the $>0.25-\mathrm{mm}$ macroaggregates were gradually broken into $<0.25-\mathrm{mm}$ microaggregates. This result was consistent with that of Legout et al. [28], who proposed that soil aggregates could be hypothesized into a single stratified structure. The macroaggregates $(>0.25 \mathrm{~mm})$ were bound by microaggregates $(<0.25 \mathrm{~mm})$ and gradually disintegrated into microaggregates during rainfall. The macroaggregates were mainly broken into $0.25-0.053-\mathrm{mm}$ aggregates for all rainfall experiments (Figure 5). Fu et al. [41] considered that the $E R$ value of particle sizes $1-0.053 \mathrm{~mm}$ was greater than 1 . Aggregates with a particle size $>1 \mathrm{~mm}$ were mainly broken into aggregates with particle sizes of $1-0.053 \mathrm{~mm}$ in the single-raindrop test in that study. That particle size was larger than the results of this study, because the single-raindrop splash soil resulted in less fragmentation of the aggregates [41]. Conversely, in a study with multineedle rainfall, soil particles may receive secondary raindrop splash erosion, and hence more fine particles may be produced.

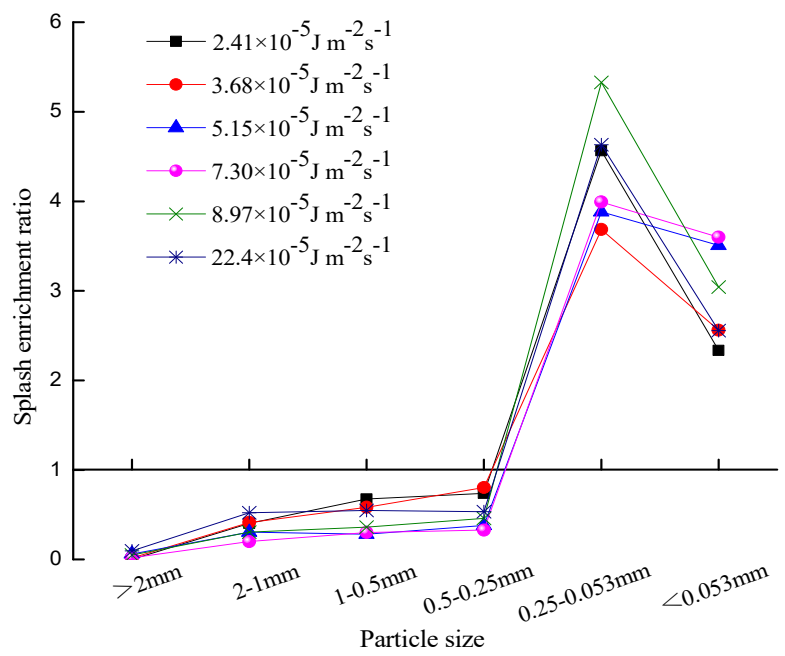

Figure 5. Splash enrichment ratio $(E R)$ for each particle size of the different raindrop energy levels.

\section{Conclusions}

This study analyzed the soil splash erosion amounts and the distribution of particle sizes under six rainfall conditions at five splash distances. Dark loessial soil with a Corg content (Organic Carbon) of $1.6 \%$ and natural moisture of $18.8 \%$ and a core size of $10 \times 20 \mathrm{~cm}$ was used in laboratory experiments.

The splash erosion amounts of the six raindrop conditions were mainly distributed at distances of $0-20 \mathrm{~cm}$. For each raindrop energy level, the mass percentage of soil aggregates $>2 \mathrm{~mm}$ was almost zero. As a whole, the mass percentage of particle sizes $>0.25 \mathrm{~mm}$ presented a down-up trend. A particle size of $0.25 \mathrm{~mm}$ was the critical particle size level for the enrichment and depletion of splash erosion.

A model was obtained to predict the splash erosion amount for the rainfall energy and splash distance, which could evaluate the soil splash erosion in the Loess Plateau well, but the simulation results of the areas outside the Loess Plateau are still insufficient. Therefore, model correction needs further exploration in future research.

The fractal dimension $(D)$ of the aggregates showed a downward opening parabolic relationship with raindrop energy. The maximal raindrop energy value was $1.29 \times 10^{-4} \mathrm{~J} \mathrm{~m}^{-2} \mathrm{~s}^{-1}$, which broke the 
aggregates to the largest degree. The above results provide insights into the variation in aggregates in the soil layer during rainfall and a good understanding of soil surface crust and soil erosion mechanisms.

Author Contributions: Conceptualization, Y.F., G.L., and D.W.; data curation, Y.F.; formal analysis, Y.F., G.L., and D.W.; funding acquisition, G.L.; investigation, Y.F., G.L., D.W., and T.Z.; methodology, Y.F.; project administration, G.L.; resources, D.W.; software, Y.F. and G.L.; supervision, G.L.; validation, Y.F. and G.L.; writing一original draft, Y.F.; writing-review and editing, Y.F., G.L., D.W., T.Z. and M.Y.

Funding: This work was supported by the National Natural Science Foundation of China (41571262) and the Chinese Ministry of Water Resources Science and Technology Promotion (TG1308).

Acknowledgments: The authors thank anonymous reviewers for insightful comments on the original manuscript. This work was supported by the National Natural Science Foundation of China (Grant. No. 41571262) and the Chinese Ministry of Water Resources Science and Technology Promotion program (TG1308).

Conflicts of Interest: The authors declare no conflict of interest.

\section{References}

1. Kinnell, P.I.A. Raindrop impact induced erosion processes and prediction: A review. Hydrol. Process. 2005, 19, 2815-2844. [CrossRef]

2. Hu, F.N.; Liu, J.F.; Xu, C.Y.; Wang, Z.L.; Liu, G.; Li, H.; Zhao, S.W. Soil internal forces initiate aggregate breakdown and splash erosion. Geoderma 2018, 320, 43-51. [CrossRef]

3. Li, G.L.; Fu, Y.; Li, B.Q.; Zheng, T.H.; Wu, F.Q.; Peng, G.Y.; Xiao, T.Q. Micro-characteristics of soil aggregate breakdown under raindrop action. Catena 2017, 162, 354-359. [CrossRef]

4. Xiao, H.; Liu, G.; Abd-Elbasit, M.A.M.; Zhang, X.C. Effects of slaking and mechanical breakdown on disaggregation and splash erosion. Eur. J. Soil Sci. 2017, 68, 797-805. [CrossRef]

5. Wuddivira, M.N.; Stone, R.J.; Ekwue, E.I. Clay, Organic Matter, and Wetting Effects on Splash Detachment and Aggregate Breakdown under Intense Rainfall. Soil Sci. Soc. Am. J. 2009, 73, 226-232. [CrossRef]

6. Fernández-Raga, M.; Palencia, C.; Keesstra, S.; Jordán, A.; Fraile, R.; Angulo-Martínez, M.; Cerdà, A. Splash erosion: A review with unanswered questions. Earth-Sci. Rev. 2017, 171, 463-477. [CrossRef]

7. Ramos, M.C.; Nacci, S.; Pla, I. Effect of raindrop impact and its relationship with aggregate stability to different disaggregation forces. Catena 2003, 53, 365-376. [CrossRef]

8. Saedi, T.; Shorafa, M.; Gorji, M.; Khalili, M.B. Indirect and direct effects of soil properties on soil splash erosion rate in calcareous soils of the central Zagross, Iran: A laboratory study. Geoderma 2016, 271, 1-9. [CrossRef]

9. Lado, M.; Benhur, M.; Shainberg, I. Soil wetting and texture effects on aggregate stability, seal formation, and erosion. Soil Sci. Soc. Am. J. 2004, 68, 1992-1999. [CrossRef]

10. Yakubu, M.L.; Yusop, Z.; Fulazzaky, M.A. The influence of rain intensity on raindrop diameter and the kinetics of tropical rainfall: Case study of Skudai, Malaysia. Int. Assoc. Sci. Hydrol. Bull. 2016, 61, 944-951. [CrossRef]

11. Sajjadi, A.S.; Mahmoodabadi, M. Aggregate breakdown and surface seal development influenced by rain intensity, slope gradient and soil particle size. Solid Earth 2015, 6, 311-321. [CrossRef]

12. Cheng, J.; Qin, Y.; Zhang, H.; Cong, Y.; Yang, F.; Yan, Y.Q. Splash erosion under artificial rainfall in Rocky mountain area of northern China. Trans. Chin. Soc. Agric. Mach. 2015, 46, 153-161.

13. Ziadat, F.M.; Taimeh, A.Y. Effect of rainfall intensity, slope, land use and antecedent soil moisture on soil erosion in an arid environment. Land Degrad. Dev. 2013, 24, 582-590. [CrossRef]

14. Lim, Y.S.; Jin, K.K.; Kim, J.W.; Park, B.I.; Kim, M.S. Analysis of the relationship between the kinetic energy and intensity of rainfall in Daejeon, Korea. Quatern. Int. 2015, 384, 107-117. [CrossRef]

15. Free, G.R. Erosion characteristics of rainfall. Agric. Eng. 1960, 41, 447-449.

16. Dijk, A.I.J.M.V.; Bruijnzeel, L.A.; Rosewell, C.J. Rainfall intensity-kinetic energy relationships: A critical literature appraisal. J. Hydrol. 2002, 261, 1-23. [CrossRef]

17. Angulo-Martínez, M.; Beguería, S.; Navas, A.; Machín, J. Splash erosion under natural rainfall on three soil types in NE Spain. Geomorphology 2012, 175, 38-44. [CrossRef]

18. Dai, X.; Zhang, H.T.; Zhou, D.M. Introduction to artificial rainfall simulator and its application. Soil Water Conserv. China 2012, 12, 52-54. 
19. Shainberg, I.; Mamedov, A.I.; Levy, G.J. Role of wetting rate and rain energy in seal formation and erosion 1. Soil Sci. 2003, 168, 54-62. [CrossRef]

20. Hu, W.; Zheng, F.; Bian, F. The Directional Components of Splash Erosion at Different Raindrop Kinetic Energy in the Chinese Mollisol Region. Soil Sci. Soc. Am. J. 2016, 80, 38-44. [CrossRef]

21. Wang, D.; Li, G.L.; Fu, Y.; Gao, G.X.; Zheng, T.H. Detachment and transport characteristics of sandy loam soil by raindrop action in the northern loess plateau, China. J. Soil Water Conserv. 2018, 73, 705-713. [CrossRef]

22. Ellison, W.D. Studies of raindrop erosion. Agric. Eng. 1944, 25, 181-182.

23. Ellison, W.D. Two devices for measuring soil erosion. Agric. Eng. 1944, 25, 53-55.

24. Morgan, R.P.C. Field studies of rainsplash erosion. Earth Surf. Proc. Land. 1978, 3, 295-299. [CrossRef]

25. Ma, R.M.; Li, Z.X.; Cai, C.F.; Wang, J.G. The dynamic response of splash erosion to aggregate mechanical breakdown through rainfall simulation events in Ultisols (subtropical China). Catena 2014, 121, 279-287. [CrossRef]

26. Dijk, A.I.J.M.V.; Meesters, A.G.C.A.; Bruijnzeel, L.A. Exponential distribution theory and the interpretation of splash detachment and transport experiments. Soil Sci. Soc. Am. J. 2002, 66, 1466-1474. [CrossRef]

27. Ellison, W.D. Soil erosion studies. Parts I and II. Agric. Eng. 1947, 28, 197-201.

28. Legout, C.; Leguédois, S.; Le Bissonnais, Y. Aggregate breakdown dynamics under rainfall compared with aggregate stability measurements. Eur. J. Soil Sci. 2005, 56, 225-238. [CrossRef]

29. The Ministry of Water Resources of the People's Republic of China; Chinese Academy of Sciences; Chinese Academy of Engineering. Water Loss and Soil Erosion and Ecological Security of China: The Loess Plateau; Science Press: Beijing, China, 2010.

30. Fu, Y.; Li, G.L.; Zheng, T.H.; Zhang, T. Splash detachment and transport of loess aggregate fragments by raindrop action. Catena 2017, 150, 154-160. [CrossRef]

31. Yao, W.Y.; Chen, G.X. Calculation formula of rain drop fall velocity. J. Hohai Univ. 1993, 21, $21-27$.

32. Jiao, J.Y.; Wang, W.Z.; He, X.P. Precipitation and erosion characteristics of rain-storm in different pattern on Loess Plateau. J. Arid Land Resour. Environ. 1999, 13, 34-42.

33. Yang, P.L.; Luo, Y.P.; Shi, Y.C. Using weight distribution of soil particle size to express soil fractal features. Chin. Sci. Bull. 1993, 38, 1896-1899.

34. Nash, J.E.; Sutcliffe, J.V. River flow forecasting through conceptual models 1: A discussion of principles. J. Hydrol. 1970, 10, 282-290. [CrossRef]

35. Rose, C.W. Soil detachment caused by rainfall. Soil Sci. 1960, 89, 28-35. [CrossRef]

36. Parsons, A.J.; Abrahams, A.D.; Wainwright, J. Rainsplash and erosion rates in an interrill area on semi-arid grassland southern Arizona. Catena 1994, 22, 215-226. [CrossRef]

37. Fernándezraga, M.; Fraile, R.; Keizer, J.J.; Teijeiro, M.E.V.T.; Castro, A.; Palencia, C.; Calvo, A.I.; Koenders, J.; Marques, R.L.D.C. The kinetic energy of rain measured with an optical disdrometer: An application to splash erosion. Atmos. Res. 2010, 96, 225-240. [CrossRef]

38. Castrignanò, A.; Stelluti, M. Fractal Geometry and Geostatistics for describing the Field Variability of Soil Aggregation. J. Agric. Eng. Res. 1999, 73, 13-18. [CrossRef]

39. Tyler, S.W.; Wheatcraft, S.W. Fractal scaling of soil particle-size distributions: Analysis and limitations. Soil Sci. Soc. Am. J. 1992, 56, 362-369. [CrossRef]

40. Zhou, Y.Y.; Wang, E.H.; Chen, X.W. Splash erosion of black soil with different reclamation year sand its relations to soil aggregates selective characteristic. Chin. J. Appl. Ecol. 2009, 20, 2411-2416.

41. Fu, Y.; Li, G.L.; Zheng, T.H.; Zhang, T. Effects of raindrop splash on aggregate particle size distribution of soil plough layer. Trans. Chin. Soc. Agric. Eng. 2017, 33, 155-160.

(C) 2019 by the authors. Licensee MDPI, Basel, Switzerland. This article is an open access article distributed under the terms and conditions of the Creative Commons Attribution (CC BY) license (http://creativecommons.org/licenses/by/4.0/). 